\title{
El concepto de sello autorial en el cine. Los casos de Steven Spielberg y Clint Eastwood
}

\author{
Juan Enrique GonZÁLVEZ VALLÉS \\ Universidad Camilo José Cela \\ juanen2012@gmail.com
}

Recibido: 31/07/2012

Aceptado: 31/10/2012

\begin{abstract}
Resumen
A lo largo de la historia del cine se ha debatido sobre la diferencia entre los directores de cine y los autores de cine que dirigen películas. Dentro del primer grupo situaríamos a nombres con tanto renombre, y valga el deliberado juego de palabras, como Hitchcock, John Ford, John Huston, Martin Scorsese o George Lucas, entre otros. Es en este grupo donde también encontramos a dos directores que se han elevado desde la nada hasta la categoría de autores por sus propios méritos. Se trata de Steven Spielberg y de Clint Eastwood. Neoyorkino y californiano han llevado una carrera que abarca desde unos comienzos duros hasta ser considerados actualmente como leyendas del séptimo arte. Sus películas son recordadas y revisadas con el paso de los años encontrando en ellas la huella de sus directores. En el caso de Clint Eastwood, hemos encontrado también los estilemas propios de la cinematografía del californiano. Al encontrar varias producciones conjuntas entre las productoras de estos dos genios, Amblin y Malpaso, nuestra hipótesis será la de buscar la modificación en los estilemas de uno u otro al haber influencia de alguno de ellos.
\end{abstract}

Palabras clave: Steven Spielberg, Clint Eastwood, estilema, sello, cine.

\section{The Concept of Authorial Stamp on the Cinema. Cases of Steven Spielberg and Clint Eastwood}

\begin{abstract}
Throughout the history of cinema it has been discussed about the difference between film directors and authors of movies who direct films. Into the first group we would place such important names as Hitchcock, John Ford, John Huston, Martin Scorsese and George Lucas, among others. It is in this group where we also find two directors who have risen from nothing to the category of authors on its own merits. These are Steven Spielberg and Clint Eastwood. New Yorker and Californian have taken a career spanning from a tough start to be currently considered legends of cinema. His films are remembered and revised over the years, finding in them the imprint of their directors. For Clint Eastwood, we have been found his stylemes as well. Spielberg and Eastwood have several joint productions with their two companies, Amblin and Malpaso, and our hypothesis is to look at the modification of the stylemes of both and if there is an influence of any of them in the stylemes of the other.
\end{abstract}

Keywords: Steven Spielberg, Clint Eastwood, stylemes, stamp, cinema.

Referencia normalizada:

GONZÁLVEZ VALLÉS, Juan Enrique (2012): "El concepto de sello autorial en el cine. Los casos de Steven Spielberg y Clint Eastwood". Estudios sobre el mensaje periodístico. Vol. 18, núm. especial noviembre, págs.: 941-949. Madrid, Servicio de Publicaciones de la Universidad Complutense.

Sumario: 1. Introducción: el concepto de estilema. 2. Metodología. 3. Desarrollo; 3.1. Las huellas de Eastwood; 3.2. Las huellas de Spielberg. 4. Conclusiones. 5. Referencias bibliográficas.

\section{Introducción: el concepto de estilema}

Durante años hemos asistido a la búsqueda de un concepto sobre el sello autorial que sea válido y duradero: "Al contrario de un texto, la película se considera producto de varias personas" (Maurer, 2011: 19). Pero nosotros buscamos el elemento que desta- 
que al creador sobre el resto. Desde el público en general hasta los investigadores más avanzados han reconocido la presencia de marcas por las cuales cualquiera puede discernir que una determinada película pertenece a un determinado autor. No hace falta ni siquiera presenciar la totalidad del metraje de la cinta, sino que con parte de ella, podemos establecer su autoría. En ese sentido, encontramos la definición de David Caldevilla como la que reúne las características anteriormente citadas, pudiéndola constituir como base para nuestro estudio:

"Definimos sello autorial como la forma particular, personal e intransferible, aunque sí imitable, que un creador tiene de plasmar consciente o inconscientemente su aportación personal en todos y cada uno de los elementos conformantes de ese todo que llamamos obra y que como tal nos permite tomarla como objeto de nuestro estudio" (Caldevilla, 2005: 23)

\section{Metodología}

Seguiremos el esquema de Seymour Chatman (1990: 287) a la hora de utilizar la metodología más correcta para establecer los estilemas de cada uno de los autores $\mathrm{y}$, por ende, el concepto de co-estilema que queremos establecer entre Eastwood y Spielberg. El análisis narrativo audiovisual propuesto por Chatman es acertado y pertinente, puesto que tiene en cuenta todos los existentes necesarios para la creación de una obra.

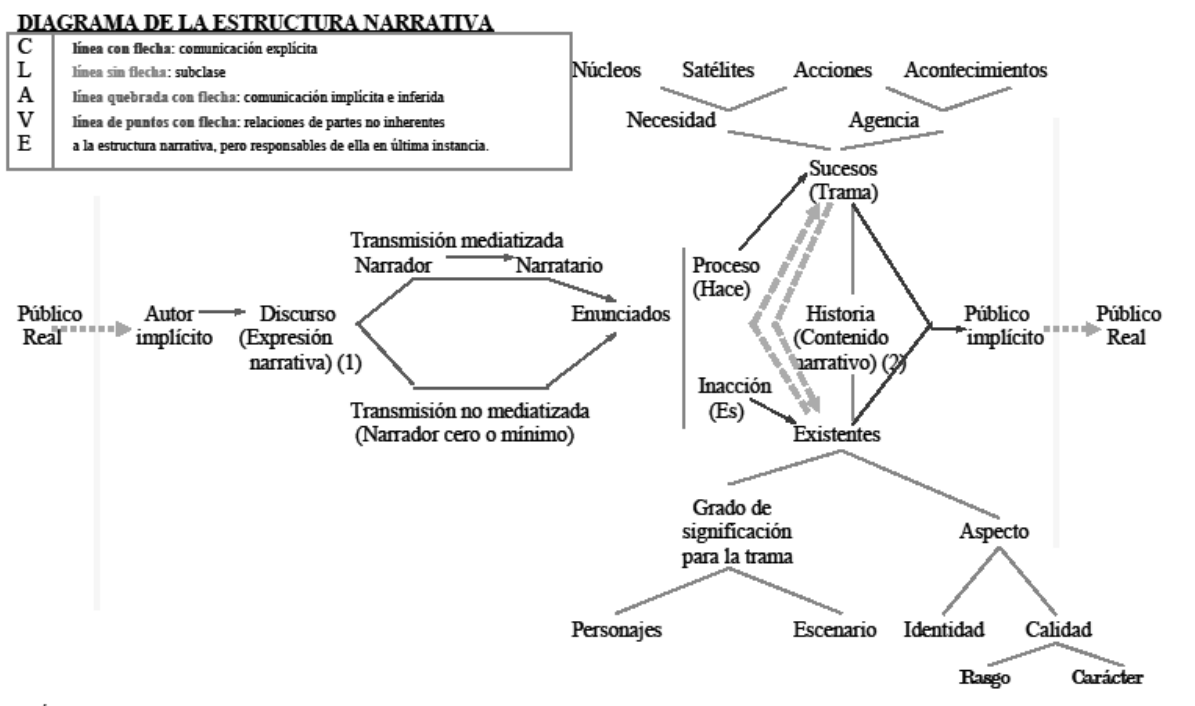
(1) Ésta es la forma de la expresión narrativa; su sustancia o manifestación aparece en varios medios (Verbales: novela, historia; Visuales: cuadros, tebeos, Audiovisuales: cine, televisión..).
(2) Ésta es la forma del contenido, no la sustancia.

Observaremos si podemos establecer estilemas autoriales en cada uno de los diferentes elementos narratológicos propuestos por Chatman. Y buscaremos como elemento de valor añadido aquellos que obtienen la categoría de co-estilemas por ser distinguibles de los demás, pero, además, tener modificaciones en el estilema de un autor (Eastwood) que están presentes en los estilemas de otro (Spielberg). 


\section{Desarrollo}

\subsection{Las huellas de Eastwood}

“«Banderas de nuestros padres» no es una película bélica convencional, aunque en su metraje sí hay secuencias bélicas. Los guionistas adaptan el libro creando una estructura narrativa, firme e ingeniosa, que funciona en varios frentes y siempre en torno a la célebre foto de Joe Rosenthal que muestra a los soldados americanos elevando la bandera en el territorio de la isla japonesa" (Palomo, 2009: 26).

Coproducida por Steven Spielberg, se nota la mano del director de "Salvar al Soldado Ryan" en este metraje. Spielberg acababa de rodar "Munich" (2005) y no quería embarcarse en otro proyecto de carácter bélico, pero su huella está latente en la buena ejecución de las escenas del desembarco y las batallas militares. Como señala Beatriz Peña (2009: 5) "entre los puntos fuertes de Spielberg destaca el cuidado de la narrativa y el efecto emotivo sobre la audiencia".

Aun así, Eastwood tenía claro que esta parte no debía ocupar más de un tercio del metraje, que además serviría de apoyo para lo que realmente quería contar, esto es, la historia de los tres soldados que izaron la bandera. El resultado final no terminó de convencer. En Estados Unidos recibió más de una crítica por no ensalzar los valores americanos y, en el extranjero, se recibió con cierta tibieza.

A Eastwood le surgió además un problema tan inverosímil como imposible, conociendo su carrera cinematográfica: "El director negro Spike Lee acusó a Clint de racismo por no haber mostrado a soldados negros en su película, cuando ellos también habían combatido en Iwo. Clint admitió que era cierto, pero que no habían estado presentes en la parte de la batalla que le ocupaba" (Schickel, 2010: 261).

Hasta aquí vendría la parte negativa de una película más que correcta, pero que deja varios interrogantes abiertos. De hecho, esa será la intencionalidad narrativa del director, que no pretende que se conciba su obra como aislada, sino como parte de un todo, y respetando sus postulados iniciales, provinientes de películas como "Primavera en Otoño" (Gonzálvez, 2009: 4). La oscuridad empieza a ser huella imborrable en las cintas del Por ello Eastwood vuelve a sorprender a todos con la confección de "Cartas desde Iwo Jima". Será la pieza que encaje con la historia de los tres soldados de la bandera y la respuesta a los interrogantes planteados. La visión japonesa de la batalla de Iwo Jima por parte de Clint Eastwood supone un complemento acertado a las historias de los tres héroes contada en "Banderas de Nuestros Padres".

Eastwood se percató de que había algo más que contar en la batalla de la isla del Pacífico. Estando reunido con Steven Spielberg y Robert Lorenz se hizo una pregunta en alto: ¿Qué sintieron los japoneses mientras defendían Iwo Jima? No era una cuestión ni fácil de hacer ni mucho menos fácil de responder cinematográficamente. El propio cineasta aporta la clave ideológica de su obra:

"En las películas de guerra con las que crecí había chicos buenos y chicos malos. La vida no es así, y la guerra tampoco. Esta película no trata sobre el triunfo o la derrota, sino sobre los efectos de esta guerra sobre los seres humanos" (Schickel, 2010: 266).

Había que comprobar si los estadounidenses estaban lo suficientemente maduros como para mirar una película que fuera solidaria con un enemigo tan feroz como fue- 
ron los japoneses en la Segunda Guerra Mundial. Vietnam acababa de cicatrizar y la Guerra de Irak estaba en su apogeo, con lo que mostrar el lado del enemigo era una apuesta arriesgada:

"Esta película rinde homenaje a todos aquellos que perdieron sus vidas mucho antes de que fuera su hora. Creo que todas esas vidas merecen un recuerdo, un respeto, del mismo modo que lo merecen las fuerzas americanas" (Palomo, 2010: 70-71).

Eastwood quedó fascinado por la figura del general Kuribayashi y se propuso reconstruir su historia. Consiguió rescatar, gracias a un contacto en Japón, parte de las cartas que el militar había enviado a su casa durante su estancia en los Estados Unidos, en los años 30 del siglo XX:

"La correspondencia mostraba a un hombre impresionado por el carácter estadounidense y una persona convencida de que sería una estupidez por parte de Japón enfrentarse a Estados Unidos. Pese a todo, era un hombre leal y con un gran sentido del deber, que evidentemente estaba dispuesto a luchar por su país llegado el caso" (Schickel, 2010: 263).

El californiano ya tenía una historia realmente personal que contar y sólo le faltaba transformarla en un guión. Confió esta tarea a Iris Yamashita, reputada cinéfila y que trabajó con denuedo para cumplir los exigentes plazos de Eastwood. El resultado, gustó y se decidió llevarlo a la pantalla:

"Mientras rodaba 'Banderas de nuestros padres', Clint reservó algunas tomas para 'Cartas desde Iwo Jima', y cuando la primera película estaba en fase de posproducción (un proceso más largo de lo habitual debido a la gran cantidad de secuencias con efectos especiales) se dedicó a rodar la segunda película, que tenía un plazo de entrega corto y contaba con un presupuesto relativamente pequeño" (Schickel, 2010: 265).

El acercamiento a la cultura nipona fue interesante aunque demasiado recurrente a los estereotipos en cuanto a la vida en el país del sol naciente. Pero sí que logra transmitir todo lo que Kuribayashi siente en medio de la batalla y el respeto con que trata a sus hombres:

"Mantiene el lacerante sentido del horror en la muerte de las películas previas de Eastwood, y revela destreza en los momentos de una crudeza dantesca, casi surrealista, entre los cuales es imborrable el suicidio colectivo de varios soldados con granadas" (Aguilar, 2009: 260-261).

No pretende demonizar a su propia patria, sino que despliega todos sus recursos narrativos para mostrar la brillante personalidad de Kurabayahi y sus hombres, tan abnegados como los soldados norteamericanos por ganar aquella batalla:

"El mayor elemento de ficción de la película se basa en la relación del general con un soldado raso al que constantemente se encuentra por casualidad y que añade un punto de humanidad cómica pero también enternecedora. Este muchacho sólo quiere sobrevivir y volver a casa para retomar su pacífica vida de panadero (y marido y padre)" (Schickel, 2010: 265).

Eastwood se muestra tan respetuoso con los japoneses que incluso recibe el permiso del gobierno nipón para rodar en la propia isla de Iwo Jima. Para no perder ni 
un ápice de autenticidad, el californiano decide rodar la película en japonés y estrenarla en este mismo idioma en las salas de cine.

"Hay una cierta ironía en el hecho de que este director tan estadounidense encuentre el paradigma de la virtud que lo define a sí mismo de un modo más significativo en un hombre formado en unas tradiciones completamente opuestas a las suyas" (Schickel, 2010: 265).

La complementación con "Banderas de Nuestros Padres" se realiza con varias secuencias donde resuelve interrogantes planteados, mostrando de nuevo su teoría sobre el espectador inteligente, al que él se dirige, contradiciendo a Dwight MacDonald, "al que Umberto Eco califica de apocalíptico en el sentido de que éste plantea un enfoque pesimista acerca de la influencia de los medios globales de comunicación" (Torres Hortelano, 2011: 54). Además, ambas poseen un contraste a la hora de la iluminación y la fotografía. Las escenas bélicas conservan los mismos matices, con claroscuros acentuados en la nocturnidad. Pero contrasta la tonalidad de los soldados americanos en sus difíciles historias personales, con el viraje casi sepia utilizado para contar la del general Kuribayashi:

"'Cartas desde Iwo Jima', y no la mucho más ambiciosa 'Banderas de nuestros padres', encabezará la lista de las diez mejores películas y competirá por los galardones más importantes del invierno del 2006. Es un ejemplo soberbio del control de un director, además de un hábil retrato de la mente de un enemigo enigmático y contradictorio. Y, sobre todo, es una obra maestra de la modestia" (Schickel, 2010: 265).

Sin embargo, Eastwood para nada se mostró arrepentido de su aventura:

"Cada película que hago me enseña algo, y por eso sigo haciéndolas. Estoy en un momento de mi vida en el que seguramente podría parar y dedicarme a jugar al golf. Pero filmando estas dos películas sobre Iwo Jima aprendí mucho sobre la guerra y el carácter. Y también aprendí mucho de mí mismo" (Schickel, 2010: 266).

\subsection{Las huellas de Spielberg}

Analizadas ya las huellas que Clint Eastwood imprime en estas dos películas, es el turno de establecer si podemos distinguir también las marcas de Spielberg en estas dos realizaciones. Aunque primero hay que apuntar que esta colaboración entre el californiano y el de Ohio no era la primera que se producía. Ambos habían colaborado ya en la excelente "Los Puentes de Madison" (1995) cuando Spielberg era el propietario de los derechos sobre el guión en el que se interesó Eastwood. Las sinergias entre sus dos productoras, Malpaso (la de Eastwood) y Amblin (la de Spielberg) fueron totales y el producto resultante obtuvo un éxito y acabado notables.

Tampoco serán estas dos historias sobre Iwo Jima la última vez en la que los dos afamados directores aúnen sus esfuerzos. "Más Allá de la Vida" (2010) supuso otro ejemplo de colaboración entre sus dos compañías. Sin embargo, en todas las coproducciones Amblin-Malpaso (o Malpaso-Amblin) Clint Eastwood va a ser el que se encargue de ejercer la dirección de la película, mientras que Spielberg se guardará el papel de productor ejecutivo.

Spielberg es especialmente tendente a esta faceta. Amblin produce muchos más proyectos de los que él dirige y el de Cincinnati se encarga de seleccionar a los di- 
rectores que él estima oportuno para la película. Esta afirmación resulta sólo verdadera a medias en cuanto a "Banderas de Nuestros Padres" y "Cartas desde Iwo Jima", puesto que no sólo es Amblin quien produce la película, sino también Malpaso, donde il capo di tutti capi es nada más y nada menos que Clint Eastwood.

Eso coloca a los dos directores, y productores, en un plano de igualdad, que pueden llegar a ser peligroso si los respectivos egos entran en juego, pudiendo llevar incluso al traste la coproducción. No parece que sea el caso de estos dos genios del séptimo arte, cuyas colaboraciones han sido varias y variadas:

"Entre sus producciones más importantes, y más recaudatorias, podemos mencionar: 'Regreso al futuro I, II y III' de Robert Zemeckis, en 1.985, 1.989 y 1.990; ‘¿Quién engaño a Robert Rabbit?' en 1.987, también dirigida por Robert Zemeckis; y 'El secreto de la Pirámide' en 1.986 dirigida por Barry Levinson. Las tres exhiben el aire familiar del universo de Spielberg, aunque el tono narrativo sea distinto en los tres casos. Pero no mucho. Todas estas producciones presentan historias que encajan claramente en su universo de ficción, ese mundo propio y enormemente reconocible en el que tanto se transparentan sus visiones e interpretaciones de la realidad contemporánea" (Caldevilla, 2005: 203).

En el caso de las coproducciones con Eastwood observamos que tanto Amblin como él mismo se implicaron en profundidad en los proyectos, pero la presencia del californiano en la dirección, y de Malpaso también, implicaba una serie de variaciones estructurales.

Lo que se ha venido a denominar como 'el toque Spielberg' podemos afirmar sin temor a equivocarnos que está presente puesto que se juntan sus características más patentes:

1. La elección de un tema propio de la cinematografía de Spielberg. Se trata de cine bélico, muy del estilo del director de "Salvar al soldado Ryan" o del productor de "Hermanos de Sangre".

2. La elección de miembros de Amblin que se integran dentro de la estructura del equipo de rodaje. Es decir, la 'familia Malpaso' adopta temporalmente a miembros de la 'familia Amblin', aunque en este caso nos remitimos fundamentalmente al propio Spielberg, cuyas reuniones con Eastwood fueron constantes para la confección de estas dos películas.

\section{Conclusiones}

$\mathrm{Al}$ referirnos a dos autores consagrados cuyo sello autorial ya ha sido puesto de manifiesto a lo largo de varias investigaciones, cabe ahora preguntarse cuál es el efecto que tiene que ambos trabajen juntos. Entre las posibles soluciones a estas preguntas estarían:

1. Que las huellas del director primen sobre las del productor, o viceversa.

2. Que existan huellas de los dos en unas determinadas proporciones.

3. Que el sello autorial de uno de los dos se vea modificado en uno o varios aspectos por la influencia del otro.

Nuestra investigación nos ha llevado a afianzarnos sobre la tercera posibilidad por diversas razones. Cuando hablamos de la existencia del sello autorial nos referimos a 
autores con suficiente personalidad como para no dejar que otro autor le coaccione para introducir sus estilemas. Además, tampoco tendría sentido que el productor se reservara sólo ese papel si su verdadero objetivo es el de implantar sus marcas en un producto cinematográfico que otro va a dirigir.

Spielberg se ha distinguido por saber influenciar a directores amigos para que realicen productos que siguen su senda cinematográfica, como ya hemos explicado, pero sus grandes obras siempre han sido dirigidas por él mismo. Igualmente podríamos hablar de Clint Eastwood, aunque en este caso la faceta de productor del californiano ha sido prácticamente residual, si no nos referimos a películas dirigidas por él mismo.

No obstante, Eastwood no ha tenido problema para dejarse aconsejar a la hora de afrontar retos nuevos para él, dirigiéndose siempre a los mejores en el terreno. El rodaje de una película bélica no era precisamente su mejor virtud y por eso las marcas de Spielberg ahí sí que están patentes. Son pequeñas modificaciones de los estilemas de Eastwood, en este caso para mejor, sin duda por la influencia del autor de Cincinnati. Es por eso que hablamos del co-estilema y no del nacimiento de una nueva unidad de estilo.

Pasamos ahora a analizar la modificación, o no, de los estilemas de Eastwood obtenidos en investigaciones previas (Gonzálvez, 2012: 1037):

1. Temática: Clint Eastwood modifica este estilema puesto que, aunque haga una historia sobre los valores estadounidenses, también aporta una visión diferente, la japonesa, sobre la historia. Sin duda, la influencia de Steven Spielberg es patente en este terreno.

2. Género: Este estilema permanece inalterado puesto que se remite a un género clásico del cine, el cine bélico en este caso, como es costumbre en la cinematografía de Eastwood.

3. Secuencia de contextualización: Eastwood quiere que el espectador se ubique cuanto antes en el contexto en el que se desarrolla físicamente la película. Para ello siempre utiliza planos generales al comienzo de la película. Esta constante es una de las más notorias de su obra y en estas dos películas también va a estar presente.

4. Dosificación de la información: Eastwood se dirige a un espectador ideal que él considera que no necesita toda la información para entender sus películas ya que la historia contada en la película se incardina entre un antes y un después dentro del discurrir de su vida. Pero en estas dos películas sí que añade ciertos elementos que provocan el misterio en el espectador. De hecho, Spielberg, genio de los bucles informativos, sabe influenciarle para que se produzcan preguntas en "Banderas de Nuestros Padres" que no se responderán hasta que se vea "Cartas desde Iwo Jima".

5. Diálogos: Quizá es el estilema más modificado por parte de Spielberg dentro del sello Eastwood. Los diálogos, normalmente utilizados por el californiano como centros de información, son ahora correa de transmisión del argumento, muy al estilo del autor de Cincinnati.

6. McGuffin: La foto de Rosenthal y las cartas de Kuribayashi son, sin lugar a dudas, los McGuffin's de ambas realizaciones. Este estilema, por tanto, permanece inalterado. 
7. Personaje fantasma: Lo es Iggy, el soldado que desaparece en medio de la batalla de Iwo Jima y cuyo recuerdo está presente en "Banderas de Nuestros Padres". No hay ningún personaje fantasma en "Cartas desde Iwo Jima", aunque pensamos que, en este caso, no existe modificación por parte de Spielberg o, por lo menos, no tenemos esa certeza.

8. Personaje del perdedor: éste es otro estilema que permanece inalterado. Desde los héroes de la bandera de Iwo Jima, convertidos en los verdaderos derrotados de la historia, hasta el propio Kuribayashi, copan este concepto tan extendido en la obra de Clint Eastwood.

9. Tratamiento del héroe: al tratarse de una película coral, y con la influencia de Spielberg, este recurso consistente en utilizar un plano contrapicado en leve ascenso, no está presente.

10. Iluminación: el intenso uso del claroscuro, muy utilizado por Eastwood, cede el protagonismo al color, casi saturado en "Banderas de Nuestros Padres" y casi vacío en "Cartas desde Iwo Jima". Es una modificación del estilema en la que vemos, una vez más, también la mano de Steven Spielberg.

11. Montaje: El grado de escritura cero es propio de los dos autores con lo que no existe ninguna novedad reseñable en este aspecto para ninguna de las dos películas.

12. Plano semisubjetivo: Muy frecuente en Eastwood, también va a ceder terreno en el rodaje de las escenas de batalla, donde los planos amplios y llenos de información serán los principales. De hecho parecen una continuación del desembarco de Normandía de "Salvar al soldado Ryan".

13. Música: Eastwood compone la banda sonora de "Banderas de Nuestros Padres" y encarga a su hijo Kyle la de "Cartas desde Iwo Jima". Padre e hijo mantienen el estilema musical sin variaciones y sin que Spielberg tenga influencia.

14. Dirección de actores: Eastwood es un gran director de actores pero no menos efectivo es Spielberg. Sin dudar de los resultados y de que el estilema de Eastwood está presente, al reservarse Spielberg el papel de productor, su influencia es menor o nula en este aspecto.

15. Dirección de equipo: la 'familia Malpaso' se hará cargo del rodaje, asegurando este estilema, aunque hay constancia de la presencia de Spielberg en reuniones de trabajo que pudieran producir variaciones en el estilema. Sin embargo, el genial director de Cincinnati no impuso cambio en el staff de producción (pre y post incluidas) dejando sin variación este estilema.

\section{Referencias bibliográficas}

CALDEVILLA, David (2005): El sello de Spielberg. Madrid. Visión Net.

CHATMAN, Seymour (1990): Historia y discurso. La estructura narrativa en la novela y en el cine. Madrid, Taurus.

GONZÁLVEZ, Juan Enrique (2009): "Primavera en Otoño de Clint Eastwood" en Revista de Comunicación Vivat Academia, $\mathrm{n}^{\circ}$ 109. Madrid. Universidad Complutense: http://www.seeci.net/vivataca/numeros/n109/Num109/PDFs/n109-Cine2.pdf 
GONZÁLVEZ, Juan Enrique (2012): El estilema autorial en el cine de Clint Eastwood. Tesis Doctoral. Madrid. Universidad Complutense (en fase de publicación).

MAURER, Isabel (2011): “Cruzando fronteras: Todo sobre mi madre (1999) de Pedro Almodóvar" en Revista de Comunicación SEECI, $\mathrm{n}^{\circ} 24$. Madrid. Universidad Complutense: http://www.ucm.es/info/seeci/Numeros/Numero 24/DATOS.html [fecha de consulta: 11 de julio de 2012]

PEÑA, Beatriz (2009): "La emoción en el cine" en Revista de Comunicación Vivat Academia, $\mathrm{n}^{\circ}$ 102. Madrid. Universidad Complutense: http://www.ucm.es/info/vivataca/anteriores/n102/DATOSS102.htm [fecha de consulta: 28 de julio de 2012]

SCHICKEL, Richard (2010): Clint Eastwood: una retrospectiva. Barcelona. Blume.

TORRES-HORTELANO, Lorenzo J. (2011): "De lo vernacular y el World Cinema en Biutiful" en Revista de Comunicación SEECI, $\mathrm{n}^{\circ}$ 24. Madrid. Universidad Complutense: http://www.ucm.es/info/seeci/Numeros/Numero 24/DATOS.html [fecha de consulta: 28 de julio de 2012] 